Journal of Thermal Engineering, Vol. 5, No. 6, Special Issue 10, pp. 221-229, December, 2019

Yildiz Technical University Press, Istanbul, Turkey

\title{
COMPARISON STUDY OF AIR AND THERMAL OIL APPLICATION IN A SOLAR CAVITY RECEIVER
}

\author{
R. Loni ${ }^{1,2}$, A.B. Kasaeian ${ }^{3, *}$, E. Askari Asli-Ardeh ${ }^{1}$, B. Ghobadian², G. Najafi²
}

\begin{abstract}
Nowadays, solar dish collector with a cavity receiver is accounted as an efficient and compact system for converting solar radiation energy into thermal energy. All of the incoming solar irradiation to the dish aperture area, is concentrated at the dish focal point where the solar receiver is located. In the current study, the thermal performance of the dish collector with a rectangular cavity receiver was evaluated. Air and thermal oil were examined as the solar working fluids. The performance of the solar dish collector was evaluated at different values of the mass flow rate ranging from 0.002 to $0.06 \mathrm{~kg} / \mathrm{s}$ as well as different solar irradiation ranging from 600 to $1200 \mathrm{~W} / \mathrm{m}^{2}$. The results revealed that the collector efficiency improved with increasing the mass flow rate and solar irradiation. The thermal performance of the solar dish collector improved with application of the thermal oil as the solar working fluid compared to the air in the investigated solar system. The results indicated the higher cavity surface temperature could be achieved by using air as the solar working fluid compared to the thermal oil.
\end{abstract}

\section{Keywords: Cavity Receiver, Mass Flow, Solar Irradiation, Thermal Oil, Air}

\section{INTRODUCTION}

Recently, the renewable energy sources are the important subject for research due to the serious environmental problems such as the fossil fuel depletion, emissions of $\mathrm{CO}, \mathrm{CO}_{2}$, global warming, and ozone depletion. Solar energy is accounted as a favorable renewable energy. Parabolic dish concentrator is a kind of efficient solar collector for converting the solar radiation energy to thermal energy or power producing. There are different kinds of absorber in the dish concentrators [1]. The cavity receivers due to their special structure are more efficiently compared to other kinds of dish absorber [2]. The solar cavity receiver absorbs the concentrated solar heat flux from the dish concentrator. The thermal heat losses from the cavity receiver are included the conduction, convection, and radiation heat losses [3].

Some researchers have investigated the performance of thedish collector using the cavity receiver numerically and experimentally. Taumoefolau et al. [4] modelled a cavity receiver with the fluent software. They investigated the effect of the cavity inclination angle on the convection heat losses. Good agreement was found between the measured and predicted values of the convection heat loss for the investigated cavity receiver. Steinfeld and Schubnell [5] proposed a semi-empirical method to determine the optimum aperture size as well as to optimum operating temperature of a solar cavity receiver. Bammert et al. [6] suggested the calculation principles of the cavity optimum dimensions for achieving the highest performance. Stine and Harrigan [7] considered the optical errors as well as the inaccuracies of tracking systems as typical errors in the solar concentrators. Sendhil and Reddy [8] investigated the performance of a fuzzy focal solar dish concentrator using three kinds of cavity receivers. They concluded that the modified cavity receiver is the preferred receiver type. Khalsa et al. [9] presented a method with CFD codes. This technique allows the incoming radiation to interact with participating media such as falling solid particles in a high-temperature cavity receiver.

The flow and heat transfer research of the cavity receiver can help to estimate the thermal performance and to optimize the design of the receiver significantly [10-14]. Harris and Lenz [15] investigated the thermal performance of a solar concentrating system with different shapes of the cavity receiver. Xiao et al. [16] were examined the thermal performance of a solar cavity receiver with and without glass cover. They considered the influence of mass flow rate This paper was recommended for publication in revised form by Regional Editor Omid Mahian

${ }^{1}$ Department of Biosystems Engineering, University of Mohaghegh Ardabili, Ardabil, Iran.

${ }^{2}$ Department of Biosystems Engineering, Tarbiat Modares University, Tehran, Iran.

${ }^{3}$ Department of Renewable Energies, Faculty of New sciences \& Technologies, University of Tehran, Tehran, Iran.

${ }^{*} E$-mail address: akasa@ut.ac.ir

Orcid id: 0000-0003-2801-2428, 0000-0002-4340-190X, 0000-0002-4048-2046, 0000-0003-4221-5950, 0000-0003-3125-3804

Manuscript Received 9 February 2018, Accepted 6 April 2018 
as well as the flow direction of the air as the working fluid. Loni et al. $[17,18]$ analytically investigated different shapes of cavity receivers. They presented the optimum structure of the cavity receivers. In another works, Loni et al. $[19,20]$ thermodynamically and exegetically studied a solar ORC system using cavity receivers. They reported the effect of different structural and operational parameters on the ORC performance. Pavlovic et al. [21, 22] numerically and experimentally examined a spiral cavity receiver as the solar receiver in the dish concentrator. The effect of wind speed was numerically and experimentally considered by [23]. They presented some models for prediction of the forced convection in a hemispherical cavity receiver. In some studies, researchers have studied the application of different nanofluids in cavity receivers [24, 21]. Loni et al. [25] predicted the cavity thermal performance using ANN method. They showed a good prediction of the thermal performance using ANN method.

In this study, a dish concentrator using a rectangular cavity receiver was thermally modeled. Air and thermal oil were used as the solar working fluid. A dish concentrator with aperture diameter of $1.8 \mathrm{~m}$ and $84 \%$ reflectivity was chosen in this research. A cavity receiver with the height equal to $1.5 \mathrm{a}$, inner tube diameter equal to $5 \mathrm{~mm}$, and the inlet temperature of the working fluid equal to $120^{\circ} \mathrm{C}$ were assumed. The performance of the solar dish collector was evaluated at different values of the mass flow rate ranging from 0.002 to $0.06 \mathrm{~kg} / \mathrm{s}$ as well as different solar irradiation ranging from 600 to $1200 \mathrm{~W} / \mathrm{m}^{2}$. The thermal performance of the dish concentrator using a cavity receiver was considered using two investigated solar working fluids. The solar dish performance was considered under variation of the mass flow rate as well as the solar irradiation. The results of the current study elicited which kind of working fluid is proper for different applications.

\section{MODEL DESIGN AND METHODOLOGY \\ Dish Collector Modeling}

A rectangular cavity receiver is investigated in this study (see Figure 1). The working fluid flows from the bottom to the top of the investigated cavity receiver. According to previous research, the contributing parameters to the temperature profile and the heat flow on the receiver wall can be separated into two components: geometrydependent and temperature-dependent $[17,18,21]$. Their research has shown that the effects of the geometrydependent factors can be found with SolTrace software as an optical analysis tool. The temperature-dependent factors including radiation, convection, and thermal conduction losses can be calculated using a thermal model.

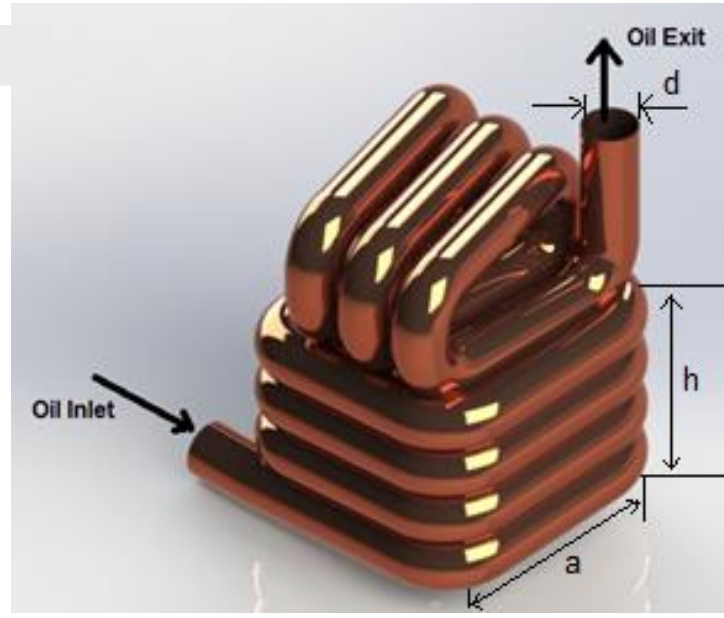

Figure 1. A rectangular open-cavity solar receiver [19].

\section{Optical Modeling}

The optical analysis is conducted using the commercial software SolTrace. This tool uses the Monte Carlo ray tracing method to perform the optical analysis. The heat flux rate over each coil of the absorber is found separately and finally, the total absorbed heat rate is found by adding the absorbed heat rate of each coil. Table 1 gives more detail about the optical analysis of the rectangular cavity receiver. 
Journal of Thermal Engineering, Research Article, Vol. 5, No. 6, Special Issue 10, pp. 221-229, December, 2019

Table 1. SolTrace modelling assumptions

\begin{tabular}{|l|c|}
\hline \multicolumn{1}{|c|}{ Parameter } & Value \\
\hline The reflectance of the cavity walls & 0.15 \\
\hline The parabolic dish rim angle & $45^{\circ}$ \\
\hline The optical errors & $10 \mathrm{mrad}$ \\
\hline The tracking error & $1^{\circ}$ \\
\hline The half-angle width & $4.65 \mathrm{mrad}$ \\
\hline The sun-shape & Pillbox \\
\hline
\end{tabular}

\section{Thermal Modeling}

The rectangular cavity receiver is covered with insulation. The heat loss from the receiver consists of convection, radiation, and conduction heat losses. The height and inner tube diameter of the investigated cavity receiver are equal to $1.5 \mathrm{a}$, and $5 \mathrm{~mm}$, respectively.

The net heat transfer rate at the receiver tube is [27]:

$$
Q_{\text {net }}=Q_{*}-Q_{\text {ioss,conduction }}-Q_{\text {ioss }, \text { rad }}-Q_{\text {ioss }, \text { conv }}
$$

While the receiver efficiency is defined as

$$
\eta_{\text {rec }}=Q_{\text {net }} / Q^{*}=m \cdot c_{\text {po }}\left(T_{\text {out }}-T_{\text {in }}\right) / \eta_{\text {optical }} \eta_{\text {refl }} Q_{\text {solar }}
$$

And

$$
\begin{gathered}
\eta_{R E C}=\eta_{\text {rec }} \cdot \eta_{\text {optical }} \\
\eta_{\text {col }}=\eta_{\text {rec }} \cdot \eta_{\text {refl }} \cdot \eta_{\text {optical }}
\end{gathered}
$$

where

$$
Q_{\text {solar }}=I \pi D_{\text {conc }}^{2} / 4
$$

For more details, see paper [17].

\section{Numerical Methods for Receiver Modeling}

The surface temperature $\left(T_{s, n}\right)$ and the net heat transfer rates $\left(Q_{\text {net }, n}\right)$ at different elements of the tube were determined by solving Eqs. (6) and (7) using the Newton-Raphson Method [21, 26].

$$
Q_{n e t, n}=\frac{\left(T_{s, n}-\sum_{i=1}^{n-1}\left(\frac{Q_{n e t, i}}{m \cdot c_{p 0}}\right)-T_{i n, 0}\right)}{\left(\frac{1}{k A_{n}}+\frac{1}{2 m \cdot c_{p 0}}\right)}
$$

And

$Q_{\text {net }, n}=Q_{n}^{* \cdot}-A_{n} \varepsilon_{n} \sigma\left(T_{s, n}{ }^{4}\right)+A_{n} \sum_{j=1}^{N} F_{n-j} \varepsilon_{j} \sigma\left(T_{s, n}{ }^{4}\right)-A_{n} \varepsilon_{n} \sigma F_{n-\infty} T_{\infty}^{4}-A_{n}\left(m_{2} T_{s, n}+c_{2}\right)-$

$\frac{A_{n}}{R_{\text {cond }}}\left(T_{s, n}-T_{\infty}\right)$ 
The receiver surface temperature at different elements of the tube and the net heat transfer rate depending on the aperture size, the height of the cavity receiver, the mass flow rate of the solar working fluid, the receiver tube diameter, the working fluid inlet temperature and the dish reflectivity. The view factors for different tube sections are shown in Tables 2 which determined via the view factor relations available at [27]. Note that, for the analysis, the receiver tube of the rectangular cavity is divided into some sections as determined by Eq. (8):

$$
N=4\left(\frac{1.5 a}{d}\right)+\frac{a}{d}=\frac{7 a}{d}
$$

Table 2. View factors for tube sections in the different part of the receiver (for $\mathrm{d}=5 \mathrm{~mm}$ )

\begin{tabular}{|l|l|l|l|}
\hline $\begin{array}{l}\text { Tube position(View } \\
\text { factor from) }\end{array}$ & $\begin{array}{l}\text { View } \\
\text { factor to }\end{array}$ & $\begin{array}{l}\text { Number of } \\
\text { transfer }\end{array}$ & View factor \\
\hline Top wall & Aperture & 1 & 0.12 \\
\hline & other & 152 & 0.005866667 \\
\hline Side wall & Top & 25 & 0.00592 \\
\hline & Across & 1 & 0.009995 \\
\hline & Left & 1 & 0.0278 \\
\hline & Right & 1 & 0.0278 \\
\hline & Aperture & 1 & 0.148 \\
\hline & Other & 111 & 0.005830183 \\
\hline
\end{tabular}

The Behran thermal oil is taken as the solar working fluid while the thermal characteristics of the Behran thermal oil are obtained by the following correlations [22]:

$$
\begin{array}{cc}
k_{f}=0.1882-8.304 \times 10^{-5}\left(T_{f}+273.15\right) & \left(\frac{W}{\mathrm{mK}}\right) \\
c_{f}=0.8132+3.706 \times 10^{-3}\left(T_{f}+273.15\right) & \left(\frac{\mathrm{kJ}}{\mathrm{kgK}}\right) \\
\rho_{f}=1071.76-0.72\left(T_{f}+273.15\right) & \left(\frac{\mathrm{kg}}{\mathrm{m}^{3}}\right) \\
\operatorname{Pr}=6.73899 \times 10^{21}\left(T_{f}+273.15\right)^{-7.7127}
\end{array}
$$

Also, the properties of the air as the working fluid were obtained by [19].

\section{RESULTS AND DISCUSSIONS Mass Flow Rate of Working Fluid}

Figure 2, and Figs. 3a and $3 \mathrm{~b}$ show the variation of the receiver efficiency, outlet temperature, and maximum cavity surface temperature versus the variety of the mass flow rate ranging 0.002 to $0.06 \mathrm{~kg} / \mathrm{s}$ for air and thermal oil as the solar working fluid, respectively. From Figure 2, it could be resulted that the collector efficiency increased with increasing the mass flow rate of the working fluid. This result of the collector efficiency is verified by the literature $[28,29]$. As seen from Figure 2, the collector efficiency shows higher values using the thermal oil compared to the air as the solar working fluid. Also, it concluded form Figure 3, the outlet temperature of the working fluids and cavity 
surface temperature decreased by increasing the mass flow rate of the working fluid. The maximum surface temperature and outlet temperature using air as the solar working fluid shows the higher values compared to the application of the thermal oil as the solar working fluid. This is because the specific heat of the thermal oil is higher than the specific heat of the air.

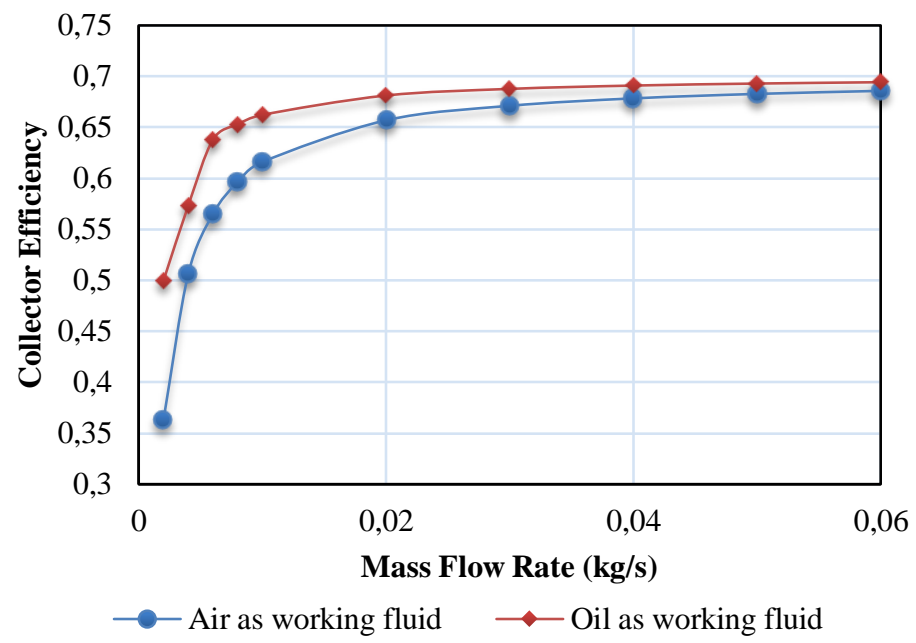

Figure 2. Variation of collector efficiency versus variation of the mass flow rate for air and thermal oil as the solar working fluid

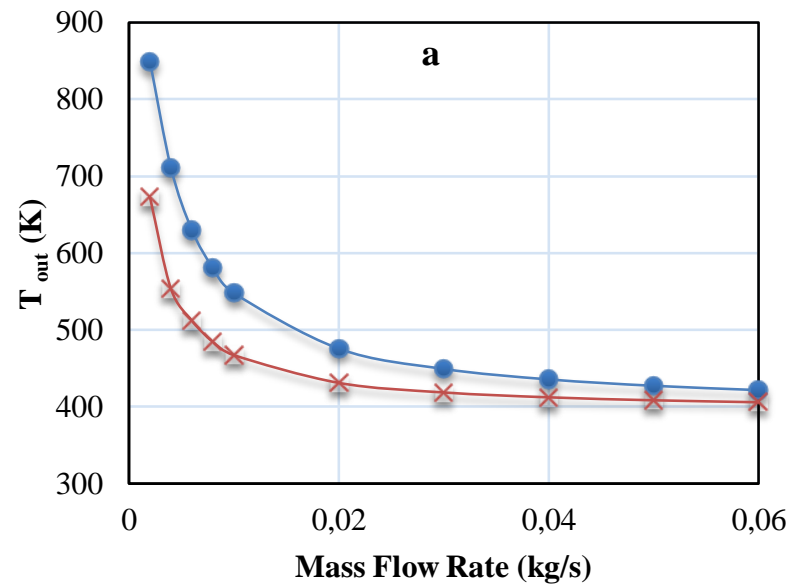

$\longrightarrow$ - Air ass working fluid $\longleftarrow$ Oil as working fluid

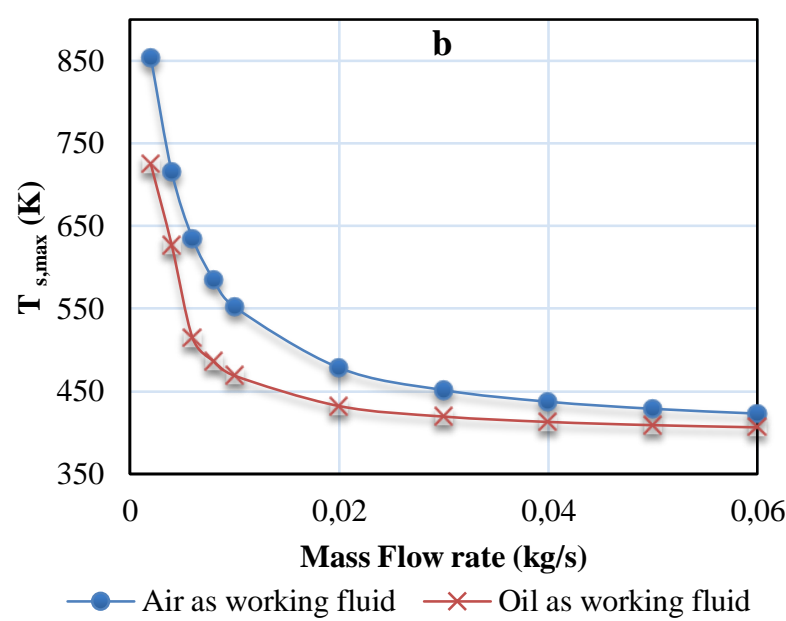

$\longrightarrow$ Air as working fluid $\rightarrow$ Oil as working fluid

Figure 3. Variation of (a) outlet temperature, and (b) maximum cavity surface temperature versus variation of the mass flow rate for air and thermal oil as the solar working fluid

\section{Solar Irradiation}

Figs. 4, 5 and 6 show the variation of the cavity heat gain, collector efficiency, and outlet temperature of the working fluid versus the variation of the solar irradiation ranging 600 to $1200 \mathrm{~W} / \mathrm{m}^{2}$, respectively. The air and the thermal oil were used as the working fluid. As resulted from Figs. 4, 5, and 6, cavity heat gain, the collector efficiency and the outlet temperature increased with increasing the solar irradiation. This issue is due to higher heat flux absorption with increasing the solar irradiation. It can result from Figs. 4, and 5, the heat gain and collector efficiency for the thermal oil have higher values compared to the air as the solar working fluid. On the other side, as seen from Figure 6, the outlet temperature of the working fluid increased by application of the air as the solar working fluid compared to the thermal oil. This is due to the thermal oil has higher thermal capacity than the air. So, it could be 
Journal of Thermal Engineering, Research Article, Vol. 5, No. 6, Special Issue 10, pp. 221-229, December, 2019

recommended that the thermal oil can be used as the solar working fluid for achieving higher thermal efficiency in the solar power systems as well as the air can be applied to achieving higher surface temperature in the Bryton cycles.

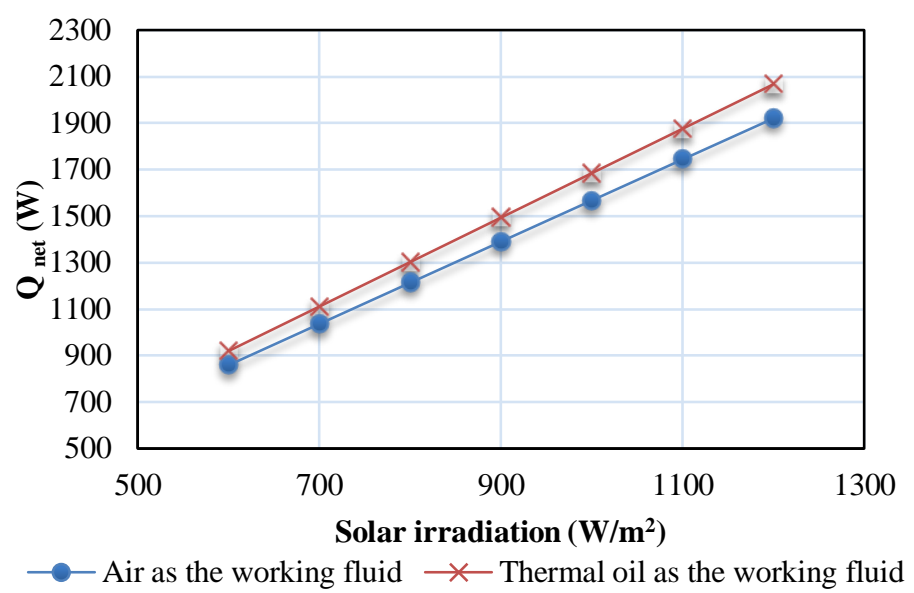

Figure 4. Variation of the cavity heat gain versus the solar irradiation for the air and the thermal oil as the working fluid at the mass flow rate of $0.01 \mathrm{~kg} / \mathrm{s}$

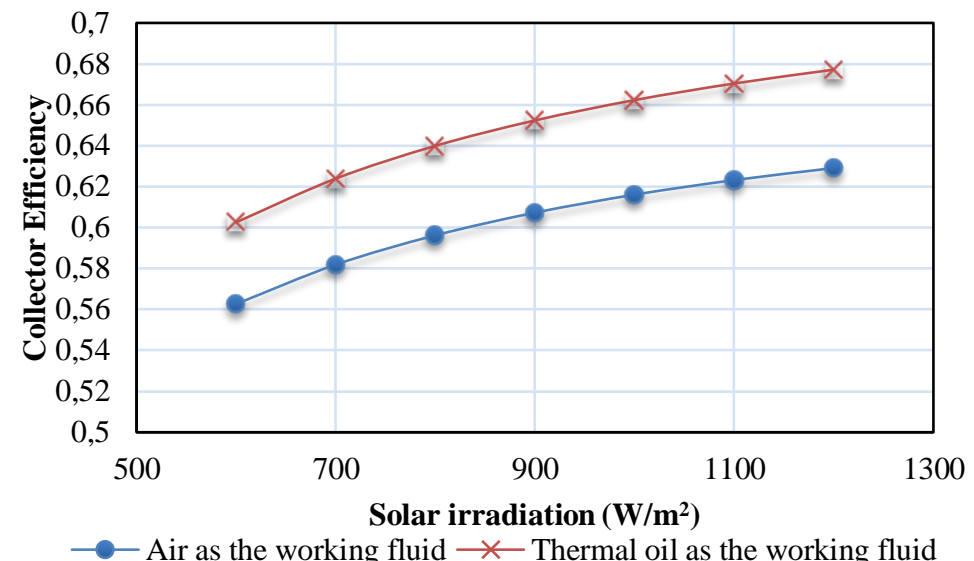

Figure 5. Variation of the collector efficiency versus the solar irradiation for the air and the thermal oil as the working fluid at the mass flow rate of $0.01 \mathrm{~kg} / \mathrm{s}$

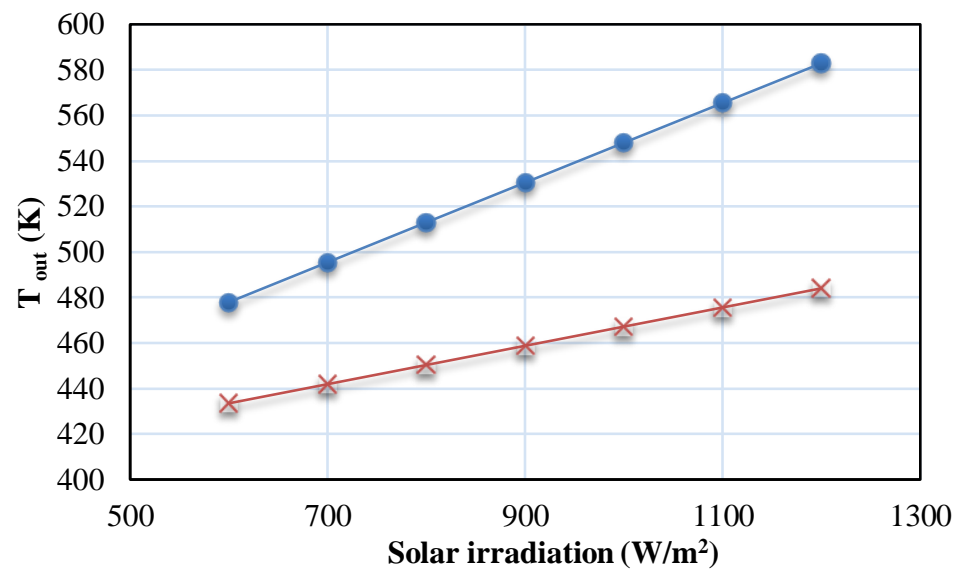

- Air as the working fluid $\rightarrow \leftarrow$ Thermal oil as the working fluid 
Figure 6. Variation of the outlet temperature versus the solar irradiation for the air and the thermal oil as the working fluid at the mass flow rate of $0.01 \mathrm{~kg} / \mathrm{s}$

\section{CONCLUSION}

In the current study, a dish concentrator with a rectangular cavity receiver is thermally investigated. Air and thermal oil were examined as the solar working fluid. The performance of solar dish collector was evaluated at different values of the mass flow rate ranging 0.002 to $0.06 \mathrm{~kg} / \mathrm{s}$ as well as different solar irradiation ranging 600 to $1200 \mathrm{~W} / \mathrm{m}^{2}$. The results were concluded as followings:

- The collector efficiency increased with increasing the mass flow rate of the working fluid.

- The outlet temperature of the working fluids and cavity surface temperature decreased by increasing the mass flow rate of the working fluid.

- The collector efficiency showed higher values using the thermal oil compared to air as the solar working fluid. Whereas, the higher cavity surface temperature and the outlet temperature can be achieved by application of air compared to the thermal oil as the working fluid.

- The collector efficiency and the outlet temperature of the working fluids increased with increasing the solar irradiation.

- Finally, it could be recommended that the thermal oil can be used as the solar working fluid for achieving higher thermal efficiency in the solar power system as well as the air can be applied to achieving higher surface temperature in the Bryton cycle.

\section{NOMENCLATURE}

\begin{tabular}{|c|c|}
\hline A & area, $\mathrm{m}^{2}$ \\
\hline $\mathrm{A}^{\prime}$ & area ratio $\left(A_{\text {ap }} / A_{\text {conc }}\right)$ \\
\hline $\mathrm{C}$ & aspect ratio \\
\hline $\mathrm{C}^{\prime}$ & optimum aspect ratio \\
\hline$c_{\mathrm{p}}$ & constant pressure specific heat, $\mathrm{J} / \mathrm{kg} \mathrm{K}$ \\
\hline d & receiver tube diameter, $\mathrm{m}$ \\
\hline D & diameter, $\mathrm{m}$ \\
\hline $\mathrm{F}$ & view factor \\
\hline $\mathrm{Gr}$ & Grasshof number \\
\hline $\mathrm{h}$ & cavity depth, $\mathrm{m}$ \\
\hline$h^{\prime}$ & heat transfer coefficient, $\mathrm{W} / \mathrm{m}^{2} \mathrm{~K}$ \\
\hline I & direct normal solar irradiance, $\mathrm{W} / \mathrm{m}^{2}$ \\
\hline $\mathrm{k}$ & thermal conductivity, W/m K \\
\hline $\mathrm{m}$ & system mass flow rate, $\mathrm{kg} / \mathrm{s}$ \\
\hline $\mathrm{Nu}$ & Nusselt number \\
\hline $\operatorname{Pr}$ & Prandtl number \\
\hline Qinet & net heat transfer rate, $\mathrm{W}$ \\
\hline$Q^{\cdot *}$ & rate of available solar heat at receiver cavity, $\mathrm{W}$ \\
\hline$Q_{\text {loss }}$ & loss rate of heat loss from the cavity receiver, $\mathrm{W}$ \\
\hline$Q_{\text {solar }}$ & rate of available solar heat at dish concentrator, $\mathrm{W}$ \\
\hline $\mathrm{R}$ & thermal resistance, $\mathrm{K} / \mathrm{W}$ \\
\hline $\mathrm{Ra}$ & Raleigh number \\
\hline $\operatorname{Re}$ & Reynolds number \\
\hline $\mathrm{T}$ & Temperature, $\mathrm{K}$ \\
\hline $\mathrm{T}$ & thickness, $\mathrm{m}$ \\
\hline$\varepsilon$ & emissivity \\
\hline$\sigma$ & Stefan-Boltzmann constant, $\mathrm{W} / \mathrm{m}^{2} . \mathrm{K}$ \\
\hline$\rho$ & density, $\mathrm{kg} / \mathrm{m}^{3}$ \\
\hline$\eta$ & efficiency \\
\hline$\alpha$ & the inclination angle of the wind direction in the horizontal surface, ${ }^{\circ}$ \\
\hline 0 & initial inlet to receiver \\
\hline
\end{tabular}


Journal of Thermal Engineering, Research Article, Vol. 5, No. 6, Special Issue 10, pp. 221-229, December, 2019

$\begin{array}{ll}\text { ap } & \text { aperture } \\ \text { Ave } & \text { average } \\ \text { col } & \text { overall for the collector } \\ \text { conc } & \text { concentrator } \\ \text { cond } & \text { due to conduction } \\ \text { Dish } & \text { dish concentrator } \\ \mathrm{f} & \text { fluid } \\ \text { inl } & \text { at the inlet } \\ \text { ins } & \text { insulation } \\ \mathrm{n} & \text { tube section number } \\ \text { optical } & \text { optical } \\ \text { out } & \text { at the outlet } \\ \text { outer } & \text { out of the cavity } \\ \text { rad } & \text { due to radiation } \\ \text { rec } & \text { receiver } \\ \text { REC } & \text { for the receiver including optical efficiency } \\ \text { receiver wall } & \text { receiver wall } \\ \text { refl } & \text { due to concentrator reflectivity } \\ \text { s } & \text { surface } \\ \text { total } & \text { total } \\ \infty & \text { environment }\end{array}$

\section{FUNDING}

Reyhaneh Loni, B. Ghobadian, and G. Najafi are grateful to the Tarbiat Modares University (http://www.modares.ac.ir) for financial supports given under IG/39705 grant for renewable Energies of Modares research group.

\section{REFERENCES}

[1] Ho, C. K., Iverson, B. D. (2014). Review of high-temperature central receiver designs for concentrating solar power. Renewable and Sustainable Energy Reviews, 29, 835-846.

[2] Gunther, M., \& Shahbazfar, R. (2011). Solar dish technology. Advanced CSP teaching materials, 1, 1-63.

[3] Harris, J. A., \& Lenz, T. G. (1985). Thermal performance of solar concentrator/cavity receiver systems. Solar energy, 34(2), 135-142.

[4] Taumoefolau, T., Paitoonsurikarn, S., Hughes, G., \& Lovegrove, K. (2004). Experimental investigation of natural convection heat loss from a model solar concentrator cavity receiver. Journal of Solar Energy Engineering, 126(2), 801-807.

[5] Steinfeld, A., Schubnell, M. (1993). Optimum aperture size and operating temperature of a solar cavityreceiver. Solar Energy, 50(1), 19-25.

[6] Bammert, K., Hegazy, A., Lange, H. (1990). Determination of the distribution of incident solar radiation in cavity receivers with approximately real parabolic dish collectors.

[7] Stine, W. B., Harrigan, R. W. (1985). Solar energy fundamentals and design.

[8] Kumar, N. S., Reddy, K. S. (2008). Comparison of receivers for solar dish collector system. Energy Conversion and Management, 49(4), 812-819.

[9] Khalsa, S. S. S., Ho, C. K. (2011). Radiation Boundary Conditions for Computational Fluid Dynamics Models of High-Temperature Cavity Receivers. Journal of Solar Energy Engineering, 133(3), 031020.

[10] Reynolds, D. J., Jance, M. J., Behnia, M., Morrison, G. L. (2004). An experimental and computational study of the heat loss characteristics of a trapezoidal cavity absorber. Solar Energy, 76(1-3), 229-234.

[11] Bertocchi, R., Karni, J., Kribus, A. (2004). Experimental evaluation of a non-isothermal high temperature solar particle receiver. Energy, 29(5-6), 687-700.

[12] Ben-Zvi, R., Karni, J. (2007). Simulation of a volumetric solar reformer. Journal of solar energy engineering, 129(2), 197-204.

[13] Yang, X., Yang, X., Ding, J., Shao, Y., Fan, H. (2012). Numerical simulation study on the heat transfer characteristics of the tube receiver of the solar thermal power tower. Applied Energy, 90(1), 142-147. 
[14] He, Y. L., Cheng, Z. D., Cui, F. Q., Li, Z. Y., Li, D. (2012). Numerical investigations on a pressurized volumetric receiver: Solar concentrating and collecting modelling. Renewable energy, 44, 368-379.

[15] Harris, J. A., Lenz, T. G. (1985). Thermal performance of solar concentrator/cavity receiver systems. Solar energy, 34(2), 135-142.

[16] Xiao, G., Yan, L., Ni, M., Wang, C., Luo, Z., Cen, K. (2014). Experimental study of an air tube-cavity solar receiver. Energy Procedia, 61, 496-499.

[17] Loni, R., Kasaeian, A. B., Asli-Ardeh, E. A., Ghobadian, B., Le Roux, W. G. (2016). Performance study of a solar-assisted organic Rankine cycle using a dish-mounted rectangular-cavity tubular solar receiver. Applied Thermal Engineering, 108, 1298-1309.

[18] Loni, R., Kasaeian, A. B., Asli-Ardeh, E. A., Ghobadian, B. (2016). Optimizing the efficiency of a solar receiver with tubular cylindrical cavity for a solar-powered organic Rankine cycle. Energy, 112, 1259-1272.

[19] Loni, R., Kasaeian, A. B., Mahian, O., Sahin, A. Z. (2016). Thermodynamic analysis of an organic rankine cycle using a tubular solar cavity receiver. Energy conversion and management, 127, 494-503.

[20] Loni, R., Kasaeian, A., Mahian, O., Sahin, A. Z., Wongwises, S. (2017). Exergy analysis of a solar organic Rankine cycle with square prismatic cavity receiver. International Journal of Exergy, 22(2), 103-124.

[21] Pavlovic, S., Bellos, E., Loni, R. (2018). Exergetic investigation of a solar dish collector with smooth and corrugated spiral absorber operating with various nanofluids. Journal of cleaner production, 174, 1147-1160.

[22] Pavlovic, S., Bellos, E., Le Roux, W. G., Stefanovic, V., Tzivanidis, C. (2017). Experimental investigation and parametric analysis of a solar thermal dish collector with spiral absorber. Applied Thermal Engineering, 121, 126135.

[23] Loni, R., Asli-Ardeh, E. A., Ghobadian, B., Kasaeian, A. B., Gorjian, S. (2017). Numerical and experimental investigation of wind effect on a hemispherical cavity receiver. Applied Thermal Engineering, 126, 179-193.

[24] Loni, R. A., Asli-Ardeh, E. A., Ghobadian, B., Kasaeian, A. B., Gorjian, S. (2017). Thermodynamic analysis of a solar dish receiver using different nanofluids. Energy, 133, 749-760.

[25] Loni, R., Kasaeian, A., Shahverdi, K., Asli-Ardeh, E. A., Ghobadian, B., Ahmadi, M. H. (2017). ANN model to predict the performance of parabolic dish collector with tubular cavity receiver. Mechanics \& Industry, 18(4), 408.

[26] Le Roux, W. G., Bello-Ochende, T., Meyer, J. P. (2014). The efficiency of an open-cavity tubular solar receiver for a small-scale solar thermal Brayton cycle. Energy Conversion and Management, 84, 457-470.

[27] Cengel Y. A. Heat and mass transfer. 3rd ed. Nevada: McGraw-Hill; 2006.

[28] Kribus, A., Doron, P., Rubin, R., Karni, J., Reuven, R., Duchan, S., Taragan, E. (1999). A multistage solar receiver:: The route to high temperature. Solar Energy, 67(1-3), 3-11.

[29] Hischier, I., Hess, D., Lipiński, W., Modest, M., Steinfeld, A. (2009). Heat transfer analysis of a novel pressurized air receiver for concentrated solar power via combined cycles. Journal of Thermal Science and Engineering Applications, 1(4), 041002. 